\title{
A ATIVIDADE CRISTIANIZADORA NA AUTO-HAGIOGRAFIA DE VALÉRIO DE BIERZO
}

\section{THE ACTIVITY OF CHRISTIANIZATION IN THE AUTOHAGIOGRAPHY OF VALERIUS OF BIERZO}

\author{
Juliana Salgado Raffaeli * \\ julianaraffaeli@hotmail.com
}

RESUMO: O presente artigo tem por objetivo o estudo das estratégias de cristianização atribuídas aos monges eremitas que teriam vivido no reino visigodo durante o século VII. Especificamente, analisamos a auto-hagiografia de Valério do Bierzo a partir das alusões às ações que visavam à expansão e à normalização do cristianismo, bem como à educação de religiosos e leigos. Nesse sentido, entendemos que o autor construiu suas narrativas com o intuito de promover um comportamento monástico considerado ideal. Acreditamos, pois, que a defesa da atuação cristianizadora foi combinada ao preceito de isolamento ascético, defendido por Valério, mas sem que tal associação descaracterizasse o seu estado de renúncia mundana, o qual estava pautado no afastamento dos laços sociais, econômicos e políticos.

PALAVRAS-CHAVE: Cristianização, Valério do Bierzo, Hagiografia.

ABSTRACT: This article aims to study the strategies of Christianization attributed to the hermit monks that lived in the Visigothic kingdom during the 7th century. Specifically, we analyze in the autohagiography of Valerio of Bierzo the allusions to actions of expansion and normalization of Christianity, as well as the education of religious and lay people. In this sense, we understand that the author built his narratives with the purpose of promoting a monastic behavior considered ideal. We believe, then, that the defense of the Christianizing activity was combined with the precept of ascetic isolation, defended by Valerius, without this association annul his state of renunciation, which was based on the removal of social, economic, and political bonds.

KEYWORDS: Christianization, Valerius of Bierzo, Hagiography.

\section{Considerações introdutórias}

Na Hispânia, as origens do monaquismo, até o fim do século IV, são pouco conhecidas pela escassez de documentos. Entretanto, por indícios pontuais, é possível afirmar que ascetas se estabeleceram na região durante a dinâmica de cristianização do Império Romano. Ainda nesse contexto, o processo de acusação e condenação como herético de Prisciliano de Ávila, estendido a seus seguidores, contribuiu para uma desconfiança eclesiástica das práticas ascéticas mais rígidas, que pudessem ser associadas ao priscilianismo. Apesar disso, a gradativa consolidação do monacato, como uma forma mais organizada de práticas ascéticas e renúncias seculares, encontrou seu ponto alto a partir do século VI, com intensas interinfluências orientais, que intermediaram a definição dos conceitos, tipologias, objetivos e regras de vida dos monges hispanos (COLOMBÁs, 2004, p. 290-295; FERNANDEZ ARDANAZ, 2000, p. 206).

\footnotetext{
* Doutora pelo Programa de Pós-graduação em História Comparada (PPGHC) da UFRJ
} 
Na península, o sucesso monástico associado ao processo de articulação entre a igreja e a monarquia visigodas, em fins do VI século, concretizaram ações de favorecimento do monacato na modalidade cenobítica, bem como normativas proibitivas em relação às formas de vida monásticas desempenhadas fora da estabilidade nos mosteiros, ou seja, sem submissão a um abade e uma regra. Os documentos produzidos sob tal perspectiva foram atas conciliares, cartas, regras monásticas, entre outros. ${ }^{1}$ Como contraponto, as hagiografias visigodas sobre monges indicavam que os hagiógrafos promoviam modelos de conduta pautados na atuação dos protagonistas que nem sempre estavam associadas a apenas um tipo de vida monástica ou estavam inseridos na modalidade mais bem aceita pela hierarquia eclesiástica, a cenobita. São os casos, por exemplo, da Vita Sancti Aemiliani, de Bráulio de Saragoça, ${ }^{2}$ e a Vita Sancti Fructuosi, de autoria desconhecida. ${ }^{3}$

A partir desta conjuntura, interessa-nos a atuação descrita por Valério de Bierzo, monge no reino visigodo durante o século VII e tradicionalmente associado ao eremitismo. $\mathrm{O}$ religioso produziu diversos textos, dentre os quais destacamos as narrativas que apresentam sua trajetória ascético-monástica no formato de hagiografia. Nesse sentido, o autor colocouse como personagem santo, digno de exemplaridade e imitação com o objetivo explícito de

\footnotetext{
${ }^{1}$ Cânones dos concílios toledanos trataram do tema dos religiosos e monges errantes, os quais deveriam ser submetidos a um mosteiro pela autoridade episcopal. O IV Concílio de Toledo (633), no cânone 53 recomenda que alguns dos eremitas fossem ordenados, enquanto outros ficassem submetidos à responsabilidade de um abade (VIVES, 1963, p. 209, c.53). Já o VII Concílio de Toledo (646), no cânone 5, reafirma que os eremitas deveriam ser encerrados em um mosteiro, para que levassem neste local uma existência religiosa regular (Ibidem, p. 255-256, c. 5). As regras monásticas produzidas por bispos no século VII também indicavam o ideal da estabilidade. Em carta dirigida a sua irmã e abadessa Florentina, Leandro de Sevilha, recomendava que as monjas não deveriam desejar voltar ao mundo ou trocar de mosteiro, além de evitar todas as formas de contato que não fossem com outras monjas, resguardar o silêncio e a moderação (LEANDRO DE SEVILHA, 1971, p. 21-76). Por sua vez, Isidoro de Sevilha produziu uma regra destinada aos monges do cenóbio honoriasense, na qual indicava que as saídas do mosteiros deveriam ser evitadas e punidas, bem como o isolamento de monges em celas eram vistos como uma recusa aos preceitos da humildade e da obediência e um risco de cair em vanglória para os monges que o buscavam e de corrupção para seus irmãos (ISIDORO DE SEVILHA, 1971, p. 90-125). Os esforços episcopais, individuais ou coletivos, indicavam um favorecimento da vida monástica em estabilidade, regida pela autoridade abacial e em cumprimento das normativas comunitárias, bem como uma preocupação com aqueles que fugiam dessa configuração, orientando as ações para o seu enquadramento (COLOMBÁS, 2004; CORULLON, 1986).

${ }^{2}$ Segundo sua hagiografia, Emiliano iniciou sua vida religiosa sob orientação do monge eremita Félix e, após ter aprendido seus ensinamentos, desempenhou a própria trajetória eremítica na região de La Rioja. Quando a notícia de sua atuação chegou ao bispo de Berceo, Dídimo, este impôs ao monge um cargo clerical, fazendo com que sua vida contemplativa fosse substituída pela ativa (BRAÚLIO DE ZARAGOZA, [s.d], c. 2-5).

${ }^{3}$ Segundo a narrativa hagiográfica, Frutuoso decide pela vida monástica após a morte de seus pais e um período de aperfeiçoamento junto ao bispo Conâncio de Palência, utilizando de sua herança para a dotação de mosteiros que organizava enquanto, paralelamente, mantinha uma atividade de monge solitário e em movimento. Este teria sido o caso da fundação do mosteiro de Compludo referenciado na Vita Valerii (La vida de San Fructuoso de Braga, 1974, p. 85, c. 2-3.).
} 
contribuir para a formação de jovens monges, por provável intermédio do abade Donadeo, a quem teria dirigido parte de suas obras. (FRIGHETTO, 2006, 7-35; DÍAZ Y DÍAZ, 2006, p. 2534)

Considerando tais propósitos enunciados pelo autor e a estruturação documental, os relatos da auto-hagiografia indicam quais comportamentos seriam considerados ideais no caminho da perfeição religiosa. Preliminarmente, identificamos que uma das principais ações narradas e, portanto, propostas como replicáveis, era o envolvimento com a atividade cristianizadora. Apesar de outro aspecto do ideal valeriano ser o isolamento ascético, tal afastamento dizia respeito ao mundo secular, em suas relações político, econômico e sociais. Ademais, a participação na difusão do cristianismo e a correção dos comportamentos dos cristãos não foram identificados na narrativa como ameaças ao estado de vida religiosa do monge. Pelo contrário, indicavam uma adequação necessária aos preceitos evangélicos.

Portanto, o presente artigo tem por objetivo analisar as referências às atividades cristianizadoras de Valério do Bierzo a partir das narrativas que compõem sua autohagiografia, categorizar tais menções a partir de suas recorrências e definir quais foram as estratégias de cristianização adotadas como exemplares pelo autor. Para alcançar tais propósitos, dividimos a abordagem em duas partes: uma síntese sobre o autor-personagem e a análise sistemática da documentação selecionada.

\section{Valério de Bierzo e sua hagiografia}

A auto-hagiografia ${ }^{4}$ do monge Valério de Bierzo é composta de três narrativas complementares. Cada relato recebeu um título, o primeiro Ordo querimonie prefati discriminis é composto de vinte e nove capítulos, o segundo Replicatio sermonorum a prima conversione, contém vinte e sete capítulos e o terceiro Quod de superioribus querimoniis residuum sequitur dispõe de seis capítulos. A edição utilizada é a versão bilíngue, latim e espanhol, de Díaz y Díaz (2006), com base no manuscrito mais completo, datado do século IX, e combinado com outras variantes parciais preservadas.

\footnotetext{
${ }^{4}$ Optamos pela utilização das expressões "auto-hagiografia" e Vita Valerii para fazer referência de forma mais objetiva ao conjunto das narrativas hagiográficas produzidas por Valério de Bierzo. O termo "Vita Valerii" foi utilizado anteriormente por Roger Collins para defender a hipótese de que os escritos do autor teriam, também, o objetivo de fornecer dados em primeira mão para a posterior produção de uma hagiografia pelos monges bercianos (COLLINS, 1986, p. 431).
} 
Segundo os dados apresentados pelo próprio monge, Valério de Bierzo teria sido membro de uma família abastada e de origem hispano-romana. As três narrativas valerianas que compõem sua auto-hagiografia foram escritas declaradamente com o objetivo de tornar o monge um exemplo para a edificação dos demais e dirigidas aos monges do Bierzo por provável mediação do abade Donadeo, autoridade do último mosteiro que Valério teria habitado, São Pedro dos Montes, para quem os registros estariam dedicados. (Ibidem, p. 3943)

A referida obra apresenta a narrativa da vida monástica do autor, assim como de alguns dos seus seguidores, críticas de cunho político e religioso aos desvios morais e dogmáticos de clérigos, comentários sobre a interferência de leigos em assuntos da esfera religiosa e os consequentes conflitos com a hierarquia eclesiástica. Segundo o autor, o início da sua trajetória religiosa foi a partir da inserção no mosteiro frutuosiano de Compludo. Após um curto período de experiência cenobítica, o monge informa ter deixado o local, sem explicitar os motivos. Na sequência, buscou o isolamento das montanhas, passando um período de reclusão que durou vinte anos. Após esse tempo de alegado aperfeiçoamento ascético, o monge passou a viver em celas próximas a construções religiosas e propriedades nobiliárquicas, atraindo a adoração popular, educando jovens nas escrituras e disseminando seus ideais monásticos por meio da formação de discípulos.

Nessas narrativas, o berciano defendia uma vida religiosa em que o isolamento seria essencial: a renúncia ao mundano, associada aos jejuns e orações, consistia no meio para alcançar a edificação espiritual (FRIGHETTO, 1997, p. 71-72). Nesse sentido, qualquer ameaça ao isolamento do asceta - como a rotina em comunidade e a vida na cidade - ou indicação à posição de prestígio foram classificadas por ele como ações diabólicas para afastá-lo de sua trajetória (SILVA, 2012, p. 61-69). Em contrapartida, as diversas formas de envolvimento com a cristianização narradas não representavam uma ameaça, mas eram louvadas e incentivadas nos escritos valerianas, aspecto sobre o qual nos debruçaremos a partir de agora.

\section{A atividade cristianizadora na Vita Valerii}

Para a nossa leitura documental, a cristianização foi considerada tanto um ideal missionário, que implicava na conversão e na pregação, quanto um anseio educador, que visava o desenvolvimento e a correção moral dos cristãos. Tais ações foram percebidas nas 
narrativas em diferentes combinações, as quais podem ser sintetizadas na ação dos monges em cristianizar populações ditas pagãs ou com práticas supersticiosas, lutar contra as heresias, posicionar-se sobre temas espirituais e morais, construir edificações religiosas, formar jovens leigos a partir dos textos considerados sagrados, educar monges como guias espirituais, entre outras possibilidades.

Com base nesse entendimento, ao analisarmos as menções a atividade cristianizadora na Vita Valerii, ${ }^{5}$ como narrada por seu hagiógrafo, o próprio Valério, encontramos dezessete (17) referências à cristianização. Tais menções podem ser organizadas em seis categorias: (6) formação de discípulos; (4) construção de edifícios religiosos; (3) educação de crianças; (2) serviço litúrgico e pregação; (1) produção e cópia de livros, e; (1) ideal cristianizador.

As referências consideravelmente mais abundantes sobre a cristianização na Vita Valeri estão relacionadas à formação de discípulos. Em diversos momentos, o hagiógrafo informa sobre a chegada, a rotina e, eventualmente, a separação de homens interessados em viver monasticamente sob a tutela de Valério. Apesar de não ser uma relação buscada pelo monge, foi narrada com entusiasmo. Soma-se a isso o dado de que a ausência de seguidores que o ajudassem na sua rotina era descrita com pesar.

Os seguidores são frequentemente identificados - Simplício, um clérigo, nobre João, Saturnino, sobrinho João e Evágrio - e têm descritos as formas como chegaram até o mestre, suas aptidões e como se desligaram, voluntária ou involuntariamente. O que nos interessa aqui, no entanto, é a preocupação com a forma como os discípulos eram incorporados na vida monástica de Valério. No primeiro caso, o hagiógrafo informa:

E desde que ele [Simplício] me ofereceu seu serviço com obediência e familiaridade, e somente nós dois permanecemos no sagrado serviço da Igreja, o diabo finalmente incitou o dito opróbrio do sacerdote [Justo] que, pela praga amaldiçoada de seu ciúme, tramando ódio contra nós, procurou como lançar novos impedimentos com muitas armadilhas, fruto enganoso de sua loucura (Ordo, p. 263, c. 14). ${ }^{6}$

\footnotetext{
${ }^{5}$ Utilizaremos para o corpo do texto a nossa tradução da versão espanhola e em notas a edição latina, identificadas por Ordo, Replicatio e Residuum, para a primeira, segunda e terceira narrativas respectivamente, presentes na versão bilíngue espanhol-latim publicada por Díaz y Díaz (2006).

6 "Quumque cum summa obedientia familiaritatis in me studeret obsequium, et nos tantum duo in quotidianum ecclesie permaneremus officium, incitauit denique inuidus diabolus ipsum sepedictum sacerdotii opprobrium, ut
} 
Simplício ofereceu seus serviços em troca de ensinamentos, também passando a compartilhar a rotina litúrgica do oratório em que Valério estava instalado. As qualidades salientadas deste primeiro discípulo são obediência e familiaridade. A presença dos dois teria insuflado a oposição do clérigo local, chamado Justo. O segundo discípulo é identificado inicialmente como um jovem clérigo que buscava à vida contemplativa:

Um clérigo que possuía a força da juventude veio a mim e com grandes orações me pediu para estar sujeito à minha disciplina. Ao vê-lo livre e adequado para artesanato, fiz dele meu assistente para minhas tarefas manuais, e encarregado de alimentos e subsídios para as nossas necessidades (Replicatio, p. 283, c. 3). ${ }^{7}$

O segundo relato segue a linha do primeiro. A adesão do seguidor estava relacionada à capacidade dele em prestar auxílios ao mestre, enquanto era preparado pela palavra e pelo exemplo. O ex-clérigo passou, portanto, a garantir as necessidades de ambos e, na sequência do relato, atuar conjuntamente no oratório e nas construções. O discípulo e ajudante teria se mantido nas graças do mestre até ser assassinado no altar.

Cabe destacar que o apoio material recebido pelos monges solitários foi referenciado em alguns escritos monásticos orientais do século $V$, principalmente, nas críticas recebidas pelos ascetas que não realizavam trabalho manual para a própria sobrevivência. Nesses casos, os eremitas ofereciam seu apoio espiritual ou pedagógico em troca dos mantimentos necessários. Não apenas as comunidades cristãs buscavam este tipo de serviço, mas neófitos se colocavam a disposição de seus mestres, com a prerrogativa de garantir a provisão para os dois. Para os críticos desse sistema, a ação dos monges que não trabalhavam sobrecarregava as comunidades que os sustentavam e acentuavam os riscos do orgulho e da vaidade (CANER, 2002, p. 42-47; DUNN, 2003, p. 19). Nesse sentido, a Vita Valerii apresenta episódios que se enquadram em ambas as possibilidades: a relação de dependência mestre-discipular e a provisão trazida por admiradores. Quando a companhia dos fiéis ou discípulos cessava, o monge reclamava de estar sozinho, mas em um sentido que não afetava o seu estado de contemplação, pois se referia ao que considerava necessário para manter-se nessa condição.

etiam pre nimia inuidiose malitie peste contra nos diu machinans odium, multis supplantationibus fallacis amentie sue incutere niterentur impedimentum." (Ordo, p. 262, c. 14).

7 "Uenit ad me quidam clericus iuuentutis fortitudine fretus, flagitans precabatur ut mee esset discipline subiectus. Quem intuens expeditum atque secularibus exercitiis aptum, constitui eum operum manuum mearum prodemtorem, alimentique stipendiorum necessitudinis nostre esse ministrum." (Replicatio, p. 282, c. 3). 
Retornando para a narrativa, o terceiro discípulo de Valério também teve sua origem identificada, um jovem nobre, que estava sendo preparado para o casamento e para assumir as funções político-sociais de sua família:

(...) [Deus] animou a vir junto de mim, um jovenzinho na flor da idade, de nome João. Seus pais estavam buscando esposa para ele, porém ele, incendiado pela chama do Espírito Santo e animado pelo desejo de abraçar a vida monástica, 'considerou melhor uma boda espiritual com Deus, que se começa com choros, mas com eles se chega a gozos eternos, do que passar por uma boda carnal, que começa sempre com alegrias e se chega ao final com lutos'. Nesse ponto, rechaçou toda a atração lasciva do mundo e veio a toda velocidade consolar minha pequenez (Replicatio, p. 293-295, c. 12). ${ }^{8}$

Nessa passagem, o hagiógrafo indica com mais clareza que se tornar um seguidor de Valério significava abraçar a vida monástica. Nesse sentido, uma das mais recorrentes formas de preocupação com o tema da cristianização parece estar relacionada com a replicação do modelo idealizado pelo monge, inicialmente entre os primeiros adeptos e na própria obra como um todo, destinada ao mosteiro de Rufiana e ao abade Donadeo (DIAZ Y DIAZ, 2006, p. 39-43). Já Saturnino, o quarto discípulo, é o que recebe a maior atenção da narrativa hagiográfica. Saturnino foi descrito quase como um "novo Valério", ele possuía todas as características necessárias para a vida eremítica, dedicado em realizar o serviço litúrgico e o atendimento aos fiéis que buscavam o oratório gerido pelos dois ascetas.

(...) trouxe o Senhor, pela compunção de seu coração, de umas terras distantes, a um rapaz, chamado Saturnino, muito disposto ao exercício da vida ativa e ao serviço, muito comedido em todo o seu comportamento, a quem recebi a princípio como um converso, porém depois que vi que cumpria com as abstinências, as vigílias, os jejuns, as orações, o canto dos salmos e todo o tipo de trabalhos, e o restante dos exercícios da vida religiosa, de dia e de noite, sem faltas, começou a piedade dos cristãos que havia vacilado (...) a restabelecer-se e proporcionar a ajuda necessária. (...) a esse irmão meu em religião, Saturnino, veio outra revelação do céu, de quanto antes, deixando aquele [João], veio a fazer companhia em minha desventura (Replicatio, p. 295-297, c. 14). ${ }^{9}$

\footnotetext{
8 "(...) excitauit quendam adulescentem iuuentutis flore uernantem, nomine Iohannem. Quum illi a parentibus suis peteretur sponsa, ille uero Spiritus Sancti flamma succensus, sancteque religionis desiderio afflatus, elegit potius spiritualibus nuptiis copulare Deo, in quibus a lucto incipitur sed ad gaudia eterna perueniatur, quam carnalibus nuptiis subici, que letitia semper incipiunt et ad fine cum luctu tendunt. Confestim uniuersa seculi inlecebrantem lasciuia despexit et ad consolationem exiguitatis mee omni cum festionantione peruenit." (Replicatio, p. 292-295, c. 12).

9 "(...) adduxit Dominus per conpunctionem cordis ex longinquitate terrarum quendam puerum, nomine Saturninum, exercitiis actiue, uite atque seruitiis aptum et in omni sua actione conpositum, quem primum ille suscipiens conuersum, quumque in summa abstinentia, uigiliis, ieiuniis, orationibus, psalmodie canoribus, diuersisque operibus artificiis, uel ceteris regularibus exercitiis, diebus ac noctibus instanter uacaret, cepit ad
} 
Saturnino foi inicialmente discípulo do jovem nobre João, que havia sido afastado de Valério após um ataque sofrido por ambos. Após se recuperar, foi impedido de voltar para a companhia do mestre e construiu um novo mosteiro nas saias da mesma montanha que o eremita habitava. O novo discípulo, portanto, estava previamente instruído pelo antigo e, então, passava a uma forma mais avançada de treinamento. Ao final da relação dos dois, entretanto, o autor narra que Saturnino foi mordido pelo espírito da vanglória, considerado o maior mal dos monges, ${ }^{10}$ e passa a competir com Valério, tornando-se recluso no oratório e descuidando das necessidades do mestre. Por fim, acaba fugindo do local com animais e livros compilados pelo mestre. Após esse desfecho, temos o relato conjunto dos dois últimos discípulos: o também chamado João, sobrinho do protagonista, e Evágrio, servo dele.

(...) o filho do meu irmão Montano, que se chamava João, veio para o meu lado com compulsão de coração, havia deixado o serviço do rei, sua mulher, seus filhos, e tudo o que tinha, converteu-se junto com um servo chamado Evágrio, entregou-se de coração ao serviço do Senhor, a quem agora serve trabalhando fielmente em tudo que é necessário para as duas celas (Replicatio, p. 305, c. 25). ${ }^{11}$

Novamente, a conversão para a vida monástica sob tutela valeriana significaria o serviço do discípulo para a manutenção de ambos os ascetas. Chama atenção, nesse caso, que o familiar em questão era funcionário real e casado, mas teria obtido autorização para a sua nova condição de vida, elemento atestado em outras duas passagens, nas quais o hagiógrafo menciona a boa vontade real com Valério (Ordo, p. 273, c. 23; Replicatio, p. 305, c. 25).

Por fim, uma referência que se enquadra na preocupação com a formação de discípulos e a cristianização, mas sem apresentá-los diretamente, foi destacada para compor esta categoria por apresentar o propósito consciente do hagiógrafo ao produzir a primeira das narrativas hagiográficas, Ordo, que depois foram reforçadas por Replicatio e Residuum:

eos christianorum pietas, (...) recurrere et necessaria stipendia ministrare (...) idem religioso fratri Saturnino sepe per reuelatione uenit admonitio ut inde quantotius egrediens ad infelicitatis mee festinaret consortium." (Replicatio, p. 294-297, c. 14).

10 Segundo Isidoro de Sevilha, em sua tipologia monástica presente na obra De Eclesiasticiis Officiis, os circunceliões são os maus monges que vagabundeiam sem rumo fixo e se vangloriam de seus feitos, um dos vícios mais perigosos para os ascetas (ISIDORO DE SEVILHA, 2007, p. 134, c. XVI).

11 "(...) fratris mei Montani filium, nomine lohannem, qui conpuncto corde ueniens reliquit seruitium regis, atque uxorem et filios uel omnia que habebat, et conuertens cum famulo suo Euagrio se toto corde dominico mancipauit seruitio, qui nunc usque que utrisque cellulis necessaria sunt fideliter elaborans ministrat." (Replicatio, p. 304-305, c. 24). 
Das muitas dificuldades e desastres, resumi alguns; não me induz a narrar o que aconteceu ao temperamento de minha vaidade, mas a minha intenção de que seja claro para todos que desejam converter-se ao Senhor na santa disciplina monástica, quão grandes são os obstáculos prejudiciais de todos os tipos de inimigos invejosos e perseguidores, e as desonestas e variadas perversidades de inveja por parte dos perdidos, e como aqueles que perseveram na luta receberão a vitória e a palma da mão do triunfo (Ordo, p. 277, c. 27$).{ }^{12}$

Considerando a declaração de Valério, a intenção na produção do texto foi levar a sua experiência para aqueles que desejavam se converter à disciplina monástica. Tanto aqueles que o buscavam diretamente quanto os que receberiam a obra no mosteiro Rufianense, ou posteriormente, com a sua provável difusão. Portanto, a educação discipular, direta ou indireta, estaria permeada no propósito de escrita do documento. Nesse sentido, todos os ideais propagados nele podem ser entendidos como exemplos dignos de imitação.

A importância da formação clerical para a composição dos quadros eclesiásticos ficou atestada nos sínodos visigodos. No século VI, uma consciência da importância de uma educação formal, para garantir o controle das disputas teológicas, ganha forma. A preocupação eclesiástica leva a criação de escolas episcopais, que davam aos bispos a responsabilidade pela formação dos que pretendiam seguir a carreira clerical. O II Concílio de Toledo (VIVES, 1963, p. 43, c. 2) apresenta duas estratégias principais para orientar o trabalho educador-pastoral: a cristianização das populações rurais e a formação de crianças e jovens destinados ao clero. Tais estratégias estavam destinadas, respectivamente, às realidades do Noroeste da Hispânia e às províncias mais conectados ao poder central (UDAONDO PUERTO, 2003). Entendemos, dessa forma, que Valério, como conhecedor dos conteúdos normativos conciliares - pontuados direta ou indiretamente em seus escritos estava inserido, em sua concepção, nas estratégias de cristianização adotadas pela igreja visigoda. A formação adequada dos seus discípulos visaria, segundo esta perspectiva, um reforço educacional e cultural dos quadros eclesiásticos.

A região mais afastada da influência toledana, da qual Valério fazia parte, produziu relatos de práticas descritas como pagãs, que envolviam sacrifícios rituais, superstições e

\footnotetext{
12 "De innumera discriminum certamina pauca breuiter conprehensa non me conpulit temeritas uaneglorie innotescere prolata, sed ut cunctis patesceret qui desiderant in sancta religione ad Dominum conuertere, quanta sint inimici inuidentis et persequentis perniciosa obstacula, atque hominum perditorum inuidens dira diuersaque peruersitas, et qualiter perseueranti certamine confligat qui dederat palmiferam obtinere uictoriam." (Ordo, c. 27, p. 276).
} 
idolatrias. Alguns destes documentos, como De Correctione Rusticorum, de Martinho de Braga (1981), a Vita Fructuosi, de autoria desconhecida (1974), a própria Vita Valerii, também indicam as estratégias de cristianização adotadas pelos monges (UDAONDO PUERTO, 2003). Constitui-se, no nosso entendimento, uma combinação dos ideais monásticos primevos do isolamento ascético com a normalização do cristianismo, que atendiam aos anseios monásticos e eclesiásticos conjunturais, os reinos romano-germânicos dos séculos VI e VII.

A segunda categoria de referências ao tema da cristianização diz respeito às construções de edifícios religiosos, aspecto que esteve conectado na Vita Valerii à preocupação com a educação da população rural berciana e definiram ações baseadas nas estratégias de "destruição" e/ou "obliteração" dos temas relativos à cultura folclórica, como sistematizado por Le Goff (1980, p. 214). A edificação era outra ação cristianizadora com referências diversas na vita não apenas sobre o processo de construção, mas também de ampliação e uso dos espaços de culto por Valério, seus discípulos, fiéis e proprietários. 0 primeiro indício dessa prática aparece na segunda narrativa hagiográfica, Replicatio. Valério apresenta como foi construído o oratório de São Félix, o qual ele passaria a habitar:

Como no topo de uma alta montanha, a insensata loucura da cegueira sacrílega continuava a manter impiamente e desajeitadamente templos consagrados aos demônios, de acordo com os ritos dos pagãos, enfim uma tão vergonhosa obscenidade foi destruída pelo trabalho dos fiéis cristãos, e com a ajuda do todo-poderoso Senhor uma igreja com o título de mártir São Felix foi construída ali mesmo (Replicatio, p. 280, c. 2). ${ }^{13}$

O oratório em questão foi construído a partir da destruição do espaço de culto descrito como pagão, indicando se tratar, segundo o hagiógrafo, de uma localidade não inteiramente cristianizada, mas que contava com uma comunidade envolvida no processo de substituição dos espaços religiosos, o que também pode ser chamado de "obliteração" (LE GOFF, 1980, p. 214). Apesar de não ter sido construído diretamente por Valério e seus discípulos, foi apresentado de forma elogiosa e contando com o apoio divino, portanto, comportamento digno de ser replicado.

\footnotetext{
13 "Quumque in excelsi montis cacumine stulta populi sacrilega cecitatis dementia profana demonum delubra inpie atque insipienter paganorum ritu excoleret, fidelium christianorum ope tandem probrosa obscenitas destruitur, opeque omnipotentis Domini in nomine sancti Felicis martyris basilica construitur." (Replicatio, p. 280, c. 2).
} 
O segundo relato apresenta a construção de um mosteiro por um discípulo de Valério que foi impossibilitado de retornar para a sua companhia após ambos sofrerem um agressão: "Depois disso, o João que eu mencionei, com a ajuda de Deus na saia do monte, pela parte de baixo, construiu um novo mosteiro, no qual o bispo, mesmo contra sua vontade, ordenou-o presbítero." (Replicatio, p. 294, c. 14$)^{14}$ Além de mais uma vez indicar que a construção de edificações cristãs era a vontade divina, o autor expõe que o bispo da região, Astorga, consagrou a construção e ordenou seu construtor. A contrariedade em aceitar cargos é também um topos hagiográfico, que revelaria tanto a humildade do beneficiado quanto, no caso de hagiografias monásticas, a inadequação de cargos eclesiásticos ao modo de vida eremítico.

A terceira referência da Vita Valerii às construções religiosas diz respeito a um oratório construído pelo discípulo de Valério, Saturnino, com orientações do mestre, o qual havia recebido uma visão divina confirmando o seu desejo na realização da edificação:

(...) Ali foi construído um santo templo em honra ao Senhor, dedicado a Santa Cruz e a São Pantaleão e outros santos mártires, que apesar da construção pequena, era grande pelo volume do empenho empregado. Este templo foi consagrado ao Senhor com toda a diligência pelo reverendíssimo bispo de Astorga, Aurélio, um homem de Deus. Ordenou presbítero Saturnino, artífice da construção com a ajuda do Senhor (Replicatio, p. 299, c. 16). ${ }^{15}$

A construção do novo oratório resultou, mais uma vez, na consagração do espaço pelo bispo e na ordenação do discípulo de Valério como presbítero. O epíscopo, Aurélio de Astorga, é considerado pelo hagiógrafo como "homem de Deus", contraposto ao seu antecessor, Isidoro de Astorga, que havia entrado em conflito com o monge, ao tentar leválo para Toledo (CASTELLANOS, 1996). Considerando as duas referências, a hagiografia transmite as consagrações e ordenações com um viés favorável, como um reconhecimento das autoridades ao esforço de envolvimento com a cristianização da sua região. O que parece consonante com as mencionadas orientações do II Concílio de Toledo.

\footnotetext{
14 "Posthec prefatus lohannes ad radicem eiusdem montis deorsum sibi, opitulante Domino, nouum construit monasterium in quo eum episcopus ordinauit contra uoluntate sua presbyterum." (Replicatio, p. 294, c. 14).

15 "Et in eodem loco in nomine sancte Crucis et sancti Pantaleonis ceterorumque sanctorum martyrum, licet breuis fabrice tantillum sed uirtutis culmine magnum, sacrum Domino constructum est templum, quod a uiro Dei reuentissimo Aurelio episcopo est cum omni diligentia Domino consecratum. Simulque huius edis opificem Saturninum, ope Domini, sacrauit presbyterum, qui dum quotidiana ibidem Domino inmolaret sacrificia." (Replicatio, p. 298, c. 16).
} 
A última referência dentro desta categoria é apresentada em Residuum, o terceiro texto das narrativas hagiográficas valerianas, que complementa um dado apresentado em Ordo. Essa nova referência trata de uma capela construída perto do mosteiro de Rufiana, local no qual Frutuoso de Braga costumava fazer suas orações:

Cortada na rocha com a ajuda de Deus, chegou-se a construir uma capela, edificação que está situada como o termo e encerramento do mosteiro. Da construção e obra, ali junto ao altar dos santos apóstolos, se escreveu brevemente a história anterior [Ordo] (Residuum, p. 313, c. 1). ${ }^{16}$

Mais uma vez uma edificação cristã por obra dos monges e seguidores é mencionada com caráter apologético e indicando o apoio divino. Ademais, segundo a narrativa, o início da produção do corpus hagiográfico teria se dado a partir desta construção, que na ocasião era habitado pelo autor.

Como terceira categoria de referências a elementos de cristianização, identificamos a formação de crianças conduzida por Valério. As três referências que compõem essa categoria estão presentes em Replicatio: "Naquele mesmo lugar cheio de necessidades me encarreguei da formação do filho de umas boas pessoas, e escrevi para ele para aumentar seu saber um livro bastante extenso" (Replicatio, p. 285, c. 6). ${ }^{17}$ Em outro trecho, "Como seguia vivendo naquele monte dominado pela imensa penúria da necessidade de todo tipo, em tempo de bonança, vinham muitas criancinhas para aprender comigo (...)" (Replicatio, p. 291, c. 9). ${ }^{18}$ E por fim, "Em outro momento, ensinava a ler a uma criança, meu aluno, a quem a generosidade divina havia dado grande capacidade de memória, que trabalhando meio ano conseguiu reter na cabeça, todo o Saltério com os Cânticos" (Replicatio, p. 293, c. 11). ${ }^{19}$ Conjuntamente, os trechos sugerem que os pais buscavam Valério para que desse a formação educacional inicial aos seus filhos.

\footnotetext{
16 "Qua excisa, ope Domini sanctum ei constructum est templum, quod est positum habitationis huius monasterii uelut terminum et claustrum. De eius constructione et hic iuxta altarii sanctorum apostolorum operatione, in superiore historia patet breuiter conprehensum." (Residuum, p. 312, c. 1).

17 "Quum in eodem necessitudinis loco quendam bonorum filium enutrirem, et illi pro eruditione precipuum conscripsissem libellum." (Replicatio, p. 284, c. 6).

18 "Quum igitur in sepedicto monte inmensa necessitudinis penuria quoarctatus persisterem, ueniebant quidem tranquillo tempore adulescentuli multi mee quoque se mancipantes doctrine." (Replicatio, p. 290-291, c. 9).

19 "Quum autem paruulum quendam pupillum litteris inbuerem, tantum dispensatio diuina dedit illi memorie capacitatem ut intra medium annum peragrans cum canticis untuersum memorie retineret psalterium." (Replicatio, p. 292-293, c. 11).
} 
Segundo a Vita Valerii, o método empregado pelo monge era a utilização de livros religiosos que ele mesmo copiava, e que aparecem em diversas outras partes da narrativa, em tramas diversas. Cabe ressaltar que Valério indicou que teve formação nas artes clássicas, logo no início de Ordo, e que seu conhecimento era vasto, considerando as amplas referências documentais, diretas e indiretas, que estão identificadas na sua produção. Nesse sentido, Valério poderia ser considerado um educador que agia nas duas estratégias apontadas pelo cânone conciliar, estava inserido na educação de jovens e discípulos que, provavelmente, fariam parte das estruturas eclesiásticas e atuava diretamente no combate às ditas superstições e idolatrias, a partir da edificação e ampliação de oratórios (FRIGHETTO, 2006, p. 7.; UDAONDO PUERTO, 2003).

Outras referências implicam a preocupação com a difusão e enraizamento do cristianismo foram categorizadas como serviço litúrgico e pregação. Tais indicações demonstram a preocupação do hagiógrafo de colocar tanto o mestre quanto seus discípulos envolvidos nas rotinas litúrgicas associados aos espaços que ocupavam, sejam estes construídos por eles ou não. O primeiro relato narra um milagre realizado por Saturnino, no oratório no qual era presbítero:

Outro dia quando se dispunha a celebrar o ofício das horas da manhã, e como as fechaduras da entrada estavam tão encaixadas que não podia abrilos, todo nervoso alcançou a janela do altar e disse a gritos: "Muito bem, senhores santos, eu vim celebrar vossa liturgia e não me deixais entrar". Dito isso, ao voltar para a entrada ouviu o ponto em que a fechadura, que por dentro travava a porta e estava obstruída, caiu no solo e deixava aberta a entrada. Vendo esta maravilha ele, e os que com ele estavam, cheios de assombro, bendisseram a Deus sumamente admirados (Replicatio, p. 301, c. 18). ${ }^{20}$

O segundo relato apresenta a celebração dos ofícios pelo próprio Valério, no oratório que ele passou a habitar após sair da cela de Frutuoso de Braga, no mosteiro de Rufiana. O trecho também informa sobre a ampliação interna da construção, para que pudesse abrigar o monge ali mesmo:

20 "Demum quum matutino tempore celembrandum adfuisset officium et claustra ingressi ita essent prepedita ut ea reserare non posset, conmotus animo ueniens ad fenestram altaris clamauit dicens: 'Bene hoc est, domini sancti, ut ueniam ad officium uestrum et ingredi me non permittatis'. Hec dicens quum ad ostium fuisset regressus, confestim audita est sera que intrinsecus claustra obserabat abstructa, procul abscedere et ingressum patefacere. Quod uidentes ipse et qui cum eo erant, in obstupore uersi, admirantes benedixerunt Deum." (Replicatio, p. 300, c. 18). 
Entretanto, quando ali eu, indigno, celebrava o ofício ao fim já sem sobressaltos no santo altar dos apóstolos, e posto que na escarpada ladeira do monte não havia nenhum lugar adequado para eu ficar, que fosse um pouco plano dada a minha fragilidade, com a ajuda de Deus, pouco a pouco, um espaço estreito mas suficiente para um pequeno átrio foi pavimentado graças ao trabalho de alguns jornaleiros (Replicatio, p. 307, c. 26). ${ }^{21}$

As duas categorias podem ser consideradas complementares, mas nem toda construção está acompanhada dos relatos de celebrações, bem como nem todos os locais ocupados para pregação e desenvolvimento litúrgico, pelo monge e seus discípulos, tiveram suas construções narradas na hagiografia. As edificações eram, portanto, tanto símbolos da vitória do cristianismo sobre as forças ditas demoníacas, que ali habitavam anteriormente, quanto polos de irradiação do cristianismo, os quais mantinham o empenho no convencimento e nas conversões a partir das práticas litúrgicas. Indicam, sem dúvida, que o hagiógrafo estava preocupado com ambos os temas ao construir os comportamentos exemplares de seu texto.

Apesar de já terem sido mencionados anteriormente, o objetivo da produção e cópia de livros religiosos também pode ser enquadrado em uma categoria específica. Além das referências já lembradas anteriormente, em Residuum, Valério indica a finalidade dessa atividade e como ela estava enquadrada dentro do propósito cristianizador de sua exemplaridade:

Os livros em vários volumes que tanto para o ofício cotidiano como para as festividades dos santos na ordem litúrgica correspondem as suas celebrações, e por outra parte outros santos escritos, enquanto aproveita para a melhora da edificação espiritual e ilustração da atividade das almas, de um conjunto e de outro, com ajuda de Deus, compus um compendio plenário para os santos altares.

Por estas obras e pela ajuda da boa gente, e o amor que me professavam, os habitantes deste lugar conceberam antipatia por ciúmes e invejas, e me causaram públicas e secretas perseguições odiosas, e até fabricaram uma infame prova no plano diabólico, em virtude do qual os já ditos e os que publicamente resultavam danificados, e os convertidos restantes mudaram seus propósitos religiosos, perturbados, se dispersaram por diversos lugares (Residuum, p. 315, c. 22).22

\footnotetext{
21 "Interdum dum iuxta sancto apostolorum ego indignus inconuulse demum presidens altario, quumque pretenso latere montis nullus planitie congruus pateret sinus nostre fragilitatis, paulisper opitulante manu Dei breuis hic sed aptus atriunculi locus opificum labore uersus est in planum." (Replicatio, p. 306, c. 26).

22 "Librorum uero uolumina tam que quotidiano officio quam pro sanctarum festiuitatum per ordine pertinent anniuersario, uel etiam diuersarum sanctarum scripturarum, quod ad edificationis profectum atque industrie
} 
Acreditamos que a produção e cópia de textos, voltados para a formação de jovens alunos e discípulos de Valério, também estava inserida em um propósito de cristianização que valorizava a educação letrada dos cristãos, era uma estratégia de garantir que suas atividades estivessem bem orientadas pelos materiais previamente filtrados pelo monge.

A última categoria sistematizada por nós, o ideal cristianizador, ficou delineado a partir dos argumentos de autoridade apresentados ao fim do corpus hagiográfico, em Residuum, que estendiam suas conclusões ao propósito de todo conjunto da obra.

Eu, ante a este duplo comportamento de caridade, por dentro e por fora, sempre recordo e observo a sentença do apóstolo Paulo que nos disse "Eu fiz tudo para todos, a fim de salvar a todos". [I Coríntios, 9, 22] A esta doutrina vou acrescentar algumas anedotas de histórias de Padres do deserto (Residuum, p. 319, c. 4). ${ }^{23}$

Nesse sentido, o hagiógrafo indica que toda a finalidade dos atos narrados sobre o protagonista foi destacar que a vida religiosa só é plena quando ela está dedicada a salvar outras almas. Para reforçar seu argumento, passa a apresentar relatos de Padres do Deserto que ilustram a mesma perspectiva. Lembramos que os eremitas foram frequentemente acusados de egoísmo espiritual pela forma que realizavam suas atividades religiosas, em isolamento contemplativo (ARRANZ GUZMAN, 1985, p. 11; FREITAS, 1997, p. 128-129). Entretanto, segundo a Vita Valerii, um eremita perfeito deveria estar envolvido ativamente na busca pela salvação dos outros, ensinando, orientando, construindo, enfim, buscando a cristianização. Em síntese, o tema da cristianização foi tratado de forma elogiosa e frequente na hagiografia de Valério do Bierzo e apresentou-se como um dos fios condutores da narrativa.

Considerações finais

No século VII, período em que Valério teria vivido e produzido sua hagiografia, a Hispânia já havia estabelecido o cenobitismo como a forma ideal de vida monástica, por

documentum proficit animarum, utraque altarioruum sanctorum iuuante Domino plenarium adcelebraui conpendium. Pro quibus operibus et bonorum hominum occursionem, atque summe caritatis dilectionem, huius loci incole sumserunt atrocissimum zeli et inuidie liuorem atque puplicas et clandestinas odibiles persequutiones, infandaque diabolice artis adhibuerunt apodixen, per quam prefati atque eos qui puplice sunt interfecti, ceteri qui remanebant conuersi, mutata mente, turbati per diuersa sunt terra dispersi." (Residuum, p. 314, c. 2).

23 "Ego uero inter hec caritatis interius et exterius bifariam uarietatem sancti apostoli Pauli semper obseruans recordabo sententiam dicentis: Omnibus omnia factus sum, ut omnes lacrifacerem. Ad hec autem de dogma patrum pauca breuiter adiciam." (Residuum, p. 318, c. 4). 
meio de atas conciliares, regras monásticas, cartas e tratados elaborados pelo episcopado, seja por iniciativas pessoais ou coletivas. A vida comunitária apresentava vantagens para o fortalecimento e a normalização da igreja visigoda - em fase de organização e aliada à monarquia - pela manutenção dos ideais da estabilidade, da obediência abacial e da determinação de regras monásticas referendadas por porta-vozes autorizados da instituição eclesiástica (BOURDIEU, 1996, p. 85-96).

Apesar das tentativas de enquadramentos das atividades monásticas realizadas fora dos espaços legitimados, os registros documentais sobre monges eremitas não eram pouco frequentes, principalmente quando associados ao Noroeste da península, espaço no qual as formas de monacato influenciadas pelas tradições orientais e que valorizavam as práticas ascéticas mais rígidas encontravam espaço de aceitação entre os fiéis e discípulos (FERNANDEZ ARDANAZ, 2000).

Valério de Bierzo era um conhecedor da literatura hagiográfica, tendo sido responsável por uma extensa compilação destas narrativas (DÍAZ Y DÍAZ, 1951, p. 12), dos cânones conciliares e dos principais textos monásticos em circulação em seu período. Ao descrever sua própria trajetória religiosa nos moldes das Vitae, agiu de modo consciente e explicitamente declarado para fortalecer sua própria posição frente aos conflitos religiosos do seu contexto e para defender o modo de vida ascético o qual considerava mais perfeito, mas que não encontrava respaldo nas camadas mais altas da hierarquia eclesiástica visigoda. Conhecedor das críticas aos eremitas, considerados egoístas por viver uma vida contemplativa desassociada do cuidado com a comunidade que os cercava, Valério utilizou o tema da cristianização para demonstrar que o modelo de monge proposto por ele era tanto um asceta rigoroso quanto um ativo cristianizador.

O tema da cristianização na Vita Valerii era, portanto, uma preocupação que permeava todas as atividades atribuídas ao protagonista (e autor) e seus melhores discípulos. Partiu da formação de jovens aristocratas, passou pela correção dos vícios de clérigos e monges e edificações de prédios religiosos e, por fim, chegou ao objetivo máximo da própria produção das obras valerianas: educar pela exemplaridade os ascetas e monges da região. Nesse sentido, podemos afirmar que Valério estava em consonância com as ações de normalização e expansão da cristianização promovidas pela igreja visigoda do século VII, no que concerne à conversão e manutenção litúrgica das comunidades cristãs, à educação 
formal e à correção moral de monges e clérigos. Entretanto, defendia o caminho monástico eremítico como o ideal para alcançar tais propósitos, um modelo recorrentemente coibido pelo mesmo episcopado.

\section{REFERÊNCIAS BIBLIOGRAFICAS}

DOCUMENTOS IMPRESSOS

BRAULIO DE ZARAGOZA. Vida y milagros de San Millán. Edição e tradução de Toribio Minguella. Disponível em: <http://www.vallenajerilla.com/berceo/braulio/braulio.htm>. Acesso em mar. 2019.

Concilios Visigóticos e Hispano-Romanos. Edição e tradução de Jose Vives. Madrid: CSIC. Instituto Enrique Florez, 1963.

FRUTUOSO DE BRAGA. Regula monachorum. Introdução, versão e notas de Julio Campos Ruiz e Ismael Roca Melia. Madrid: BAC, 1971. p. 137-162.

ISIDORO DE SEVILHA. Regula monachorum. Introdução, versão e notas de Julio Campos Ruiz e Ismael Roca Melia. Madrid: BAC, 1971. p. 90-125.

De Los Oficios Eclesiásticos. Introdução e tradução por Antonio Viñayo González. León: Isidoriana, 2007.

La vida de San Fructuoso de Braga. Estudio y edición critica de Manuel C. Díaz y Díaz. Braga: [s.n.], 1974.

LEANDRO DE SEVILHA. Regula monachorum. Introdução, versão e notas de Julio Campos Ruiz e Ismael Roca Melia. Madrid: BAC, 1971. p. 21-76.

MARTíN DE BRAGA. Sermon contra las Superticiones Rurales. Texto revisado y traducucion de Rosario Jove Clols. Barcelona: Albir, 1981.

Regula Communis. Introdução, versão e notas de Julio Campos Ruiz e Ismael Roca Melia. Madrid: BAC, 1971. p. 172-211.

VALÉRIO DE BIERZO. Ordo querimonie prefati discriminis. Introdução, versão e notas de Manual C. Díaz y Díaz. León: Centro de Estudios e Investigación “San Isidoro", 2006. p. 246-277.

. Quod de superioribus querimoniis residuum sequitur. Introdução, versão e notas de Manual C. Díaz y Díaz. León: Centro de Estudios e Investigación “San Isidoro”, 2006. p. 312-323.

Replicatio sermonum a prima conuersione. Introdução, versão e notas de Manual C. Díaz y Díaz. León: Centro de Estudios e Investigación “San Isidoro", 2006. p. 280-311.

BIBLIOGRAFIA CITADA

ARRANZ GUZMÁN, A. Los monjes de Oriente. Cuadernos de História 16, Madrid, n. 59, p. 6-12, 1985. p. 11.

BOURDIEU, P. A linguagem autorizada: as condições sociais da eficácia do discurso ritual. In: . A economia das trocas lingüísticas. São Paulo: EDUSP, 1996. p. 85-96. 
CANER, D. Wandering, begging monks: spiritual authority and promotion of monasticism in Late Antiquity. Berkeley/Los Angeles/Londres: University of California, 2002.

CASTELLANOS, S. Conflictos entre la autoridad y el Hombre Santo. Hacia el control oficial del Patronatus Caelestis en la Hispania Visigoda. Brocar, Logroño, n. 20, 1996, p. 77-89.

COLLINS, R. The "Autobiographical" works of Valerius of Bierzo: their structure and purpose. Antiguedad y Cristianismo, Murcia, n.3, p. 425-442, 1986.

COLOMBÁS, G. El monacato primitivo. Madrid: Biblioteca de Autores Cristianos, 2004.

CORULLÓN, I. El eremitismo en las épocas visigoda y altomedieval a través de las fuentes leonesas, I. Tierras de León, León, v. 26, n. 64, p. 46-62, 1986.

DíAZ Y DíAZ, M. C. Sobre la Compilación hagiográfica de Valerio del Bierzo. Hispania sacra, Madrid, v. 4, n. 7, p. 3-25, 1951.

Isidoro, 2006.

Valerio Del Bierzo. Su persona. Su obra. León: Centro de Estudios e Investigación San

DUNN, Marylin. The emergence of monasticism. From the Desert Fathers to the Early Middle Ages. Cornwall: Blackwell, 2000.

FERNANDEZ ARDANAZ, S. O monaquismo oriental en la Hispania de los siglos VI-X. Antiguidad y cristianismo, Murcia, n. 16, 2000, p. 203-214.

FREITAS, E. C. As Regras Monásticas de São Basílio de Cesaréia e as relações de poder no Oriente Romano no século IV. Dimensões, Vitória, n. 5, 1997, p. 128-134.

FRIGHETTO, R. O modelo de vir sanctus segundo o pensamento de Valério do Bierzo. Helmantica, Salamanca, v. XLVIII, n. 145-146, p. 59-79, 1997.

Valério do Bierzo. Autobiografia. Edição crítica. La Coruña: Toxosoutos, 2006. p. 7-50.

LE GOFF, J. Cultura Clerical e Tradições Folclóricas na Civilização Merovíngia. In: . Para um novo conceito de Idade Média. Lisboa: Estampa, 1980. p. 207-219.

SILVA, L. R. O diabo na vida de um santo: uma análise complementar da autobiografia de Valério do Bierzo. Acta Scientiarum. Education, Maringá, v. 34, n. 1, p. 61-69, 2012.

UDAONDO PUERTO, F. J. El sistema escolar en la Hispania visigoda: El ejemplo de Valerio del Bierzo. Helmantica, Salamanca, v. 54, n. 164, p. 391-445, 2003. 